\title{
Surface Modification of Fumed Silica by Dry Silanization for PP/POE-based Dielectric Nanocomposites
}

\author{
Xiaozhen $\mathrm{He}^{1}$, Ilkka Rytöluoto ${ }^{2,3}$, Amirhossein Mahtabani ${ }^{1}$, Eetta Saarimäki ${ }^{2}$, Kari Lahti ${ }^{3}$, Mika Paajanen ${ }^{2}$, \\ Rafal Anyszka ${ }^{1}$, Wilma Dierkes ${ }^{1}$, Anke Blume ${ }^{1}$ \\ 1 University of Twente, Faculty of Engineering Technology, Department of Mechanics of Solids, Surfaces \& Systems (MS3), \\ Chair of Elastomer Technology and Engineering, Enschede, The Netherlands \\ 2 VTT Technical Research Centre of Finland Ltd, Tampere, Finland \\ 3 Tampere University, High Voltage Engineering, Tampere, Finland
}

\begin{abstract}
-
A systematic study of the influence of surface modification of nanosilica with coupling agents having different polarities on the dielectric properties of a PP/POE/silica blend was performed. The main goal of this investigation was to tailor the chemical composition of the silica surface, in order to modify the charge trapping properties of the nanocomposites. For the modification of the silica surface, a "green" approach was utilized: a dry silanization method, which is performed without the need of a solvent. The results of the thermogravimetric analysis (TGA) indicate that the dry process is an effective method to perform silica surface modification using alkoxysilanes.
\end{abstract}

The charge trapping properties were studied by Thermally Stimulated Depolarization Current (TSDC) measurements. The obtained TSDC results show significant differences in charge trapping properties of PP/POE composites filled with differently modified silicas. Polar functional groups attached to the surface of the silica appear to have a strong effect on the charge trapping properties: The trap depth distribution becomes deeper and the trap density decreases to significantly lower levels.

All results show that incorporation of surface modified nanosilica into a PP/POE matrix is a promising approach to tailor its dielectric properties. Further development of these composites may lead to benefits for application in high-voltage cable and capacitor applications.

Keywords: silica surface modification, dry silanization, charge trapping, PP, POE, TSDC, high voltage cable.

\section{Introduction}

Cross-linked polyethylene (XLPE) is a widely used insulation material for high voltage cables. However, XLPE is difficult to recycle due to its thermosetting nature. Considering the concept of environmental protection and sustainable development, polypropylene as a recyclable matrix has shown great potential for new polymeric insulation materials. Due to the poor flexibility of polypropylene, blending with a thermoplastic elastomer (poly(ethylene-co-octene) - POE) has drawn significant attention; especially for developing of the next-generation thermoplastic insulation for HVDC cables. Although PP/POE blends exhibit improved flexibility in comparison to PP [1,2], they are still facing the same problems of space charge accumulation [2] which can increase the local electric field and can result in faster degradation and, finally, electrical breakdown of the insulation material.

One of the current approaches for suppressing the space charge is to design the molecular structure of the polymer matrix. It is reported that maleic anhydride (MAH) promotes the formation of polar carbonyl groups grafted onto PP macromolecules, and results in effective suppression of space charge injection and accumulation [3].

Another approach is to prepare nanodielectrics by incorporating certain nanofillers into a polymer matrix to tailor better electrical, thermal, and mechanical properties. Nanodielectrics are potentially able to withstand higher electric field stress and can exhibit suppressed space charge accumulation, with these benefits being achievable by adjusting the filler pretreatment methods and content $[4,5]$. Based on literature, the high performance in terms of dielectric properties of nanodielectrics is mainly due to the evenly scattered large interface area of the nanoparticles, which can lead to changes in trap depth and density distribution, and hence in bulk space charge accumulation $[6,7]$.

A good dispersion of the fillers in the polymer matrix is both a challenge and a prerequisite. When particles are aggregated and agglomerated due to their surface properties and interfacial tension, in the resulting electrical properties become poor. Therefore, surface modification of nanofillers is very important in order to improve the dispersion of nanofillers in the polymer matrix [8] and to yield better dielectric properties of nanodielectrics. In this paper, a new approach of dry surface modification is introduced. Compared to the solvent-based chemical modification, dry surface modification is much more environmentally friendly because barely any waste is produced. This is also an effective way to change the silica surface properties and to reach a high level of surface modification.

In addition, a systematic investigation of the dielectric properties of the $\mathrm{PP} / \mathrm{POE} /$ modified-silica blends were 
performed by means of thermally stimulated direct current (TSDC) measurements.

\section{Experimental Part}

\section{Silica Dry Modification}

The dry modification treatment was carried on the fumed silica surface with three different silanes: an unpolar silane (trimethylethoxysilane), a silane containing delocalized electron clouds (phenyldimethylethoxysilane) and a polar silane (aminopropyltriethoxysilane). The chemical formulae of the silanes are presented in Table 1.

Table 1. Silane agents

\begin{tabular}{|c|c|c|}
\hline Silane & Full name & Structure \\
\hline TMES & Trimethylethoxysilane & $\begin{array}{c}\mathrm{CH}_{3} \\
\mathrm{I} \\
\mathrm{H}_{3} \mathrm{C}-\mathrm{Si}-\mathrm{O}^{-} \\
\mathrm{I} \\
\mathrm{CH}_{3}\end{array}$ \\
\hline $\begin{array}{l}\text { Phenyl- } \\
\text { silane }\end{array}$ & $\begin{array}{c}\text { Phenyldimethylethoxy } \\
\text { silane }\end{array}$ & $\stackrel{\mathrm{CH}_{3}}{\mathrm{CH}_{3}}$ \\
\hline $\begin{array}{l}\text { Amino- } \\
\text { silane }\end{array}$ & $\begin{array}{l}\text { Aminopropyltriethoxy } \\
\text { silane }\end{array}$ & 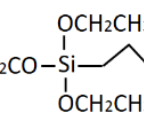 \\
\hline
\end{tabular}

The selected silanes are used to systemically study the influence of different surface modifications of the nanosilica on the charge trapping properties of the PP/POE/silica composites. This new process of dry modification was carried out in a sealed glass jar at room temperature for 24 hours. No solvent waste was produced during this modification process making it much more sustainable than the widely used solution-based methods. Therefore it is an environmentally friendly chemical modification. All the dry modifications were carried with the same amount of fumed silica $(10 \mathrm{~g})$, the same amount of catalyst 1 (0.6 g) and catalyst $2(0.2 \mathrm{~g})$, but different amounts of silane. The variation in the amount of silane based on the molecular weight is shown in Table 2. After modification, the product was placed overnight in a vacuum oven at elevated temperature (80 $\left.{ }^{\circ} \mathrm{C}\right)$ to remove unreacted agents.

Table 2. The amount of silanes used during modification

\begin{tabular}{cc}
\hline Silane & Amount/g \\
\hline TMES & 2 \\
\hline
\end{tabular}

\begin{tabular}{lc}
\hline Phenyl-silane & 3 \\
\hline Amino-silane & 3.6 \\
\hline
\end{tabular}

\section{Thermogravimetric Analysis (TGA)}

The thermogravimetric analysis was performed using a Perkin Elmer (US) TGA7 device. This characterization was done in synthetic air atmosphere with a heating rate of $20^{\circ} \mathrm{C} /$ minutes. The scanned temperature range was from ambient temperature to $850^{\circ} \mathrm{C}$.

\section{PP/POE/Silica Composite Preparation}

Various nanocomposite samples containing $1 \mathrm{wt}$. \% of the reference or modified silicas were prepared by melt-blending of the silicas with a PP/POE-based polymer blend. $12 \mathrm{~g}$ batches were compounded using a Haake MiniLab Rheomex CTW5 mini twin conical screw extruder (compounding temperature $230{ }^{\circ} \mathrm{C}$, screw speed $100 \mathrm{rpm}$ and mixing time $4 \mathrm{~min}$ ). After melt-blending, the compounds were immediately transferred to a Haake MiniJet Pro Piston Injection Molding System and injection-molded into thin sheets (size of $26 \times 26 \times 0.5 \mathrm{~mm}$ ). The injection mold temperature was $60^{\circ} \mathrm{C}$, injection temperature was $230{ }^{\circ} \mathrm{C}$, mean injection and holding pressure was 960 bar and the total injection time (injection and holding) was 40 seconds.

\section{Thermally Stimulated Depolarization Current (TSDC)}

1) The charge trapping properties were studied by Thermally Stimulated Depolarization Current (TSDC) measurements on injection molded specimens with evaporated $\mathrm{Au}$ electrodes (diameter $16 \mathrm{~mm}$ ). The TSDC procedure consisted of the following steps:

2) The samples were firstly heated up to $70^{\circ} \mathrm{C}$.

3) DC polarization field of $3 \mathrm{kV} / \mathrm{mm}$ was applied on the sample for $20 \mathrm{~min}$ under isothermal conditions at $70^{\circ} \mathrm{C}$. During polarization the charging current was measured.

4) The sample temperature was rapidly decreased to $50{ }^{\circ} \mathrm{C}$ under the same field of $3 \mathrm{kV} / \mathrm{mm}$, and then kept at this temperature for $5 \mathrm{~min}$.

5) Voltage was set to $0 \mathrm{~V}$. Then the samples were shortcircuited for 3 mins under isothermal conditions at $-50{ }^{\circ} \mathrm{C}$.

6) The samples were linearly heated up to $130{ }^{\circ} \mathrm{C}$ with a heating rate of $3{ }^{\circ} \mathrm{C} / \mathrm{min}$. Meanwhile, the depolarization current was recorded.

\section{Results and Discussion}

The modified silica particles were firstly characterized by TGA and the results are shown in Figure 1. It shows a higher weight loss of the modified silicas in comparison to the reference 
unmodified silica. This indicates that the dry process is an effective method to perform silica-silane modifications.

Based on literature [9], the evaporation of water physically adsorbed on the surface of silica particles causes a weight loss at low temperatures $\left(<200{ }^{\circ} \mathrm{C}\right)$. And the weight loss in the temperature range of $200-850{ }^{\circ} \mathrm{C}$ resulted from the chemically bonded silane and the condensation of silanol groups.

TMES and phenyl silanes contain only one ethoxy group, therefore they are not able to initiate the condensation reaction resulting in the lowest total deposition. However, the level of surface modification is higher for the silica treated with phenyl compound due to a much higher molecular weight of the phenyl ring.

Application of a tri-functional silane (aminopropyltriethoxy silane) for silica modification results in a significant amount of chemical deposition on the silica surface. This can be explained by the possible condensation of ethoxy groups leading to formation of complex oligomeric structures on the silica surface. The utilization of an amino silane for the modification resulted in a deposition exceeding $12 \%$ of the treated silica mass. This is an exceptional result in comparison to the state of the art presented in the literature [10], in which the depositions do not exceed $10 \%$ unless there is a complex, multi-step procedure involved allowing higher deposition rates [11].

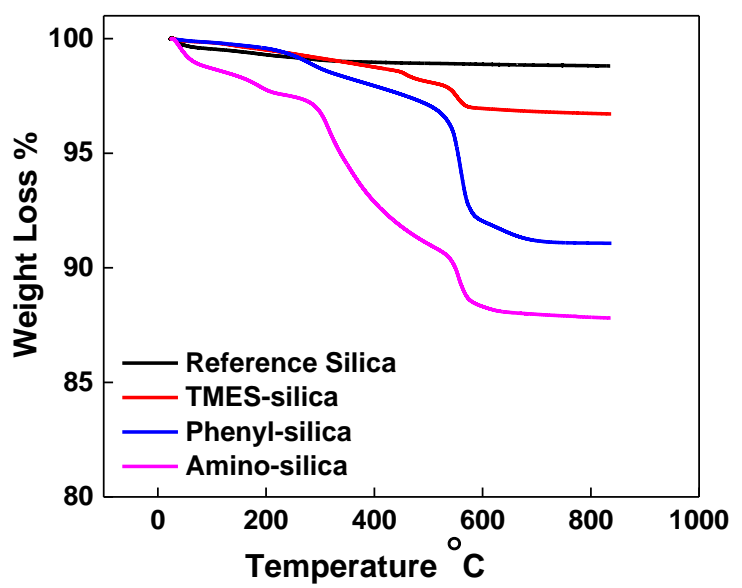

Figure 1. TGA results of reference silica and silane modified silicas.

Error! Reference source not found. shows the TSDC spectra of the injection molded PP/POE composites with the main peak at $75^{\circ} \mathrm{C}$ and a second incomplete peak onset at $120^{\circ} \mathrm{C}$. Introduction of different functional groups on the silica filler alters the charge-trapping properties in very different ways depending on the type of surface modification of the silica (Figure 2). In principle, for non-polar polymers, the TSDC values above the glass transition temperature are mostly attributed to space charge relaxation, with the temperature at peak maximum and the peak intensity being related to the depth and density of the charge traps, respectively.

For the TMES silica which is modified by an unpolar silane, the depth of the traps increases, which is visible by a shift of the maximum of the peaks of the depolarization current toward higher temperatures. Besides, the trap density also increased slightly. This might be due to the hydrophobization effect of TMES silane resulting in possibly a better dispersion of the silica in the PP/POE matrix. This leads to formation of a higher silica/PP interphase area altering the charge-trapping performance.

The phenyl silane, which contains conjugated p-orbitals (aromatic ring), also influences the electrical performance of PP/POE composites. This type of modifiers was reported to improve the dielectric properties of polymer composites [12]. In this study, the maximum of the depolarization current is slightly shifted to higher temperatures like the TMES samples in comparison to the neat PP/POE matrix. However, the chargetrapping density varies in these samples; this might be due to the difference in compatibility of the phenyl silane and TMES silane treated silicas with PP/POE matrix. The samples containing silicas modified with phenyl functionalized silanes exhibit a lower compatibility with the PP/POE matrix than the silica modified with TMES. Therefore, the charge trapping properties emerging from the silica/PP/POE interphase area are slightly suppressed.

The most interesting results were obtained by introducing the silica modified with a polar silane which contains an amine functional group. The main peak which was observed at $75^{\circ} \mathrm{C}$ for the neat PP/POE was mitigated while a new peak emerged at a higher temperature of $100{ }^{\circ} \mathrm{C}$. By introducing polar groups, the intensity of the new peak at $100{ }^{\circ} \mathrm{C}$ was also significantly lower than the main peak intensity for the other composites. This indicates that less charges have been injected into the sample during poling, and the trap distribution became deeper by adding the amino silane modified silica.

It is also noticed that incorporation of unmodified silica suppresses the very deep traps present in the PP/POE blend, which are observed as a growing peak at $120^{\circ} \mathrm{C}$. However, it seems that the incomplete second peak disappeared after introducing the silica modified by the silanes.

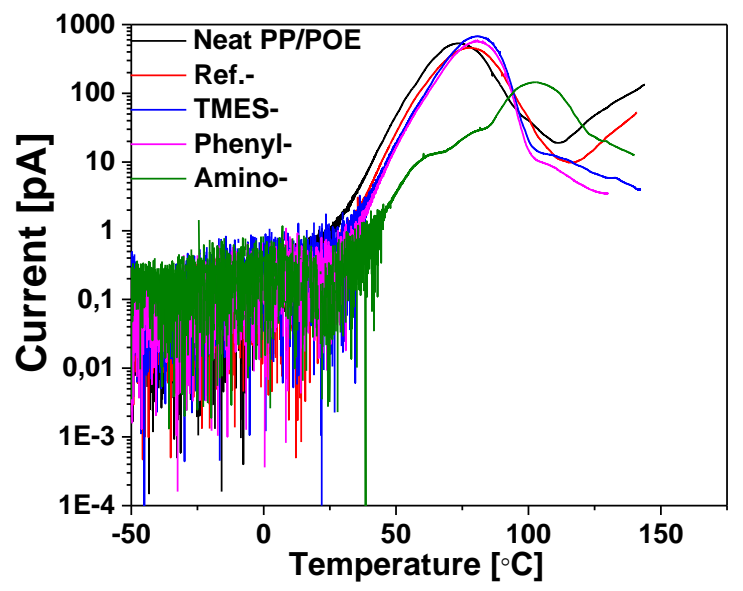

Figure 2. The TSDC results of the neat PP/POE matrix and the $\mathrm{PP} / \mathrm{POE}$ composites filled with the reference silica and the silicas modified with the silanes.

(Ref. represents the reference silica filled PP/POE; 
TMES- represents the silica modified with TMES silane filled $\mathrm{PP} / \mathrm{POE}$;

Phenyl- represents the silica modified with phenyl silane filled $\mathrm{PP} / \mathrm{POE}$;

Amino- represents the silica modified with amino silane filled PP/POE;

In order to further analyze the TSDC results, the amount of charge injected during isothermal polarization and the amount of charge released from the samples during the TSDC measurement were calculated by integrating the current vs. time curves during polarization and depolarization (Figure 3). In comparison with the neat matrix, the amount of charges injected into the sample during poling decreased for the samples filled with the reference silica and silane modified silica, indicating lower conductivity for the said compounds. It is also noticeable that a much lower amount of charges was injected into the amino silane modified silica filled composite than into the one modified with TEMS or phenyl silane.

The amount of charges which were released from the samples during the thermally stimulated phase are depicted in Figure 4. This value slightly increased for the material containing the reference silica compared to the unfilled matrix. Moreover, it becomes even higher with the silicas modified by TEMS and phenyl silane. However, there is a significant increase when incorporating the silica modified by amino silane. This means that less charges are permanently trapped or dissipated in the amino silane modified silica filled sample. In other words, incorporation of amino silane modified silica can suppress the space charge accumulation effect of the PP/POE composite.

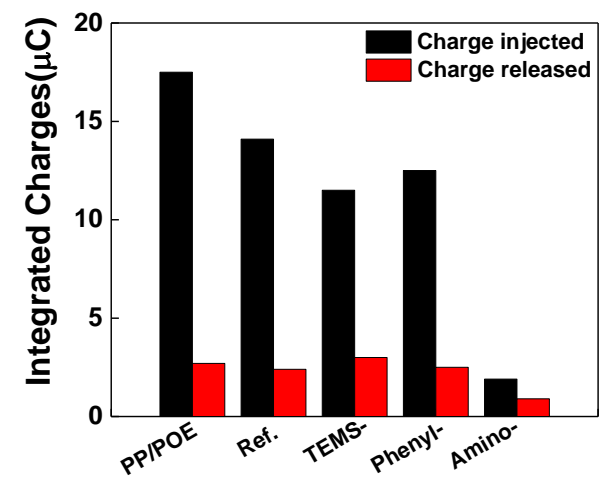

Figure 3. Amount of charge injected into or released from the samples during TSDC measurement.

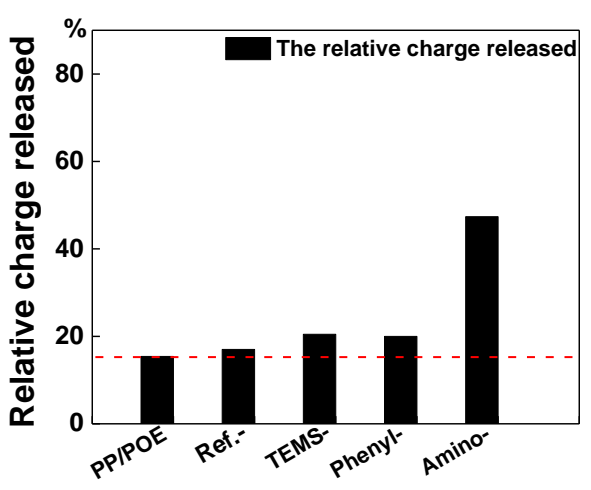

Figure 4. The relative amount of charge released from the samples during TSDC measurement.

\section{Conclusions:}

Application of the dry modification results in an effective modification of fumed nano-silica reaching a very high deposition level for the silane containing three ethoxy-functional groups. This is caused by their condensation and the silane oligomerization on the surface of the silica.

The silane containing a polar functional group has the most significant effect on the charge trapping properties of the PP/POE blends. The charge traps became deeper and the charge trap density was suppressed after adding the silica modified with the silane containing amine functional group. Based on the calculation of injected and released charge, it can imply that the net charge accumulated in Amino-silica/PP/POE is much less than in the others. It can be an indicator that Amino-silica can suppress the space charge accumulation in PP/POE composites.

\section{ACKNOWLEDGEMENTS:}

This project has received funding from the European Union's Horizon 2020 research and innovation programme under grant agreement No 720858. The authors also would like to thank the ECIU Researcher Mobility Fund for supporting this research work developed in the frame of the European 'GRIDABLE' project.

\section{References:}

[1] Zhou, Y., He, J., Hu, J., Huang, X., \& Jiang, P. Evaluation of polypropylene/polyolefin elastomer blends for potential recyclable HVDC cable insulation applications. IEEE Transactions on Dielectrics and Electrical Insulation, 22(2), 673-681. (2015).

[2] Du, B. X., Xu, H., Li, J., \& Li, Z. Space charge behaviors of $\mathrm{PP} / \mathrm{POE} / \mathrm{ZnO}$ nanocomposites for HVDC cables. IEEE Transactions on Dielectrics and Electrical Insulation, 23(5), 3165-3174. (2016).

[3] Zha, J. W., Wu, Y. H., Wang, S. J., Wu, D. H., Yan, H. D., \& Dang, Z. M. Improvement of space charge suppression of polypropylene for potential application in HVDC cables. IEEE Transactions on Dielectrics and Electrical Insulation, 23(4), 2337-2343. (2016). 
[4] Zhang, L., Zhou, Y., Cui, X., Sha, Y., Le, T. H., Ye, Q., \& Tian, J. Effect of nanoparticle surface modification on breakdown and space charge behavior of XLPE/SiO 2 nanocomposites. IEEE Transactions on Dielectrics and Electrical Insulation, 21(4), 1554-1564. (2014).

[5] Siddabattuni, S., Schuman, T. P., \& Dogan, F. Dielectric properties of polymer-particle nanocomposites influenced by electronic nature of filler surfaces. ACS applied materials \& interfaces, 5(6), 1917-1927. (2013).

[6] Roy, M., Nelson, J. K., MacCrone, R. K., Schadler, L. S., Reed, C. W., \& Keefe, R. Polymer nanocomposite dielectrics-the role of the interface. IEEE transactions on dielectrics and electrical insulation, 12(4), 629-643 (2005).

[7] Zhou, Y., Hu, J., Dang, B., \& He, J. Titanium oxide nanoparticle increases shallow traps to suppress space charge accumulation in polypropylene dielectrics. RSC Advances, 6(54), 48720-48727. (2016).

[8] Hong, R.Y.; Chen, Q. Dispersion of inorganic nanoparticles in polymer matrices: challenges and solutions. In Organic-Inorganic Hybrid Nanomaterials; Kalia, S., Haldorai, Y., eds.; Springer International Publishing: Berlin Heidelberg, Germany; pp. 1-38. (2015)

[9] Chen, G., Zhou, S., Gu, G., \& Wu, L. Modification of colloidal silica on the mechanical properties of acrylic based polyurethane/silica composites. Colloids and Surfaces A: Physicochemical and Engineering Aspects, 296(1-3), 29-36. (2007).

[10] Tang, Z., Huang, J., Wu, X., Guo, B., Zhang, L., \& Liu, F. Interface engineering toward promoting silanization by ionic liquid for high-performance rubber/silica composites. Industrial \& Engineering Chemistry Research, 54(43), 10747-10756. (2015).

[11] Qiao, B., Wang, T. J., Gao, H., \& Jin, Y. High density silanization of nano-silica particles using $\gamma$-aminopropyltriethoxysilane (APTES). Applied Surface Science, 351, 646-654. (2015).

[12] S. Siddabattuni, T. P. Schuman, and F. Dogan, "Dielectric Properties of Polymer-Particle Nanocomposites Influenced by Electronic Nature of Filler Surfaces," ACS Applied Materials \& Interfaces, vol. 5, no. 6, pp. 1917-1927, 2013/03/27 2013. 